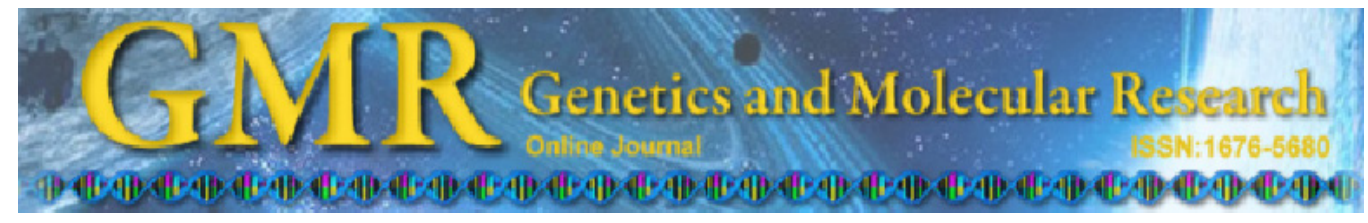

\title{
Polymorphism of somatostatin gene and its association with growth traits in Chinese cattle
}

\author{
L. Gao ${ }^{1}$, L.S. Zan ${ }^{1,2}$, H.B. Wang ${ }^{1,2}$, R.J. Hao ${ }^{1}$ and X. Zhong ${ }^{1}$ \\ ${ }^{1}$ College of Animal Science and Technology, Northwest A\&F University, \\ Yangling, Shaanxi, P.R. China \\ ${ }^{2}$ National Beef Cattle Improvement Center of Northwest A\&F University, \\ Yangling, Shaanxi, P.R. China \\ Corresponding author: L.S. Zan \\ E-mail: zanls@yahoo.com.cn
}

Genet. Mol. Res. 10 (2): 703-711 (2011)

Received August 23, 2010

Accepted December 3, 2010

Published April 19, 2011

DOI 10.4238/vol10-2gmr1029

\begin{abstract}
Somatostatins play a crucial role in the regulation of growth and development in vertebrates, especially muscle growth. We assessed the association of somatostatin gene polymorphisms with growth traits by PCR-SSCP (polymerase chain reaction-single strand conformation polymorphism) and DNA sequencing methods in 694 individuals from six Chinese cattle breeds. A novel single nucleotide polymorphism, G126A, was detected, and significant associations were found with body length, body height, hip width, heart girth, and hucklebone width index. Polymorphism of the somatostatin gene was found to be highly associated with growth traits in the Qinchuan breed at various ages. Gene frequency analysis showed significant differences among the breeds. Individuals with genotype AA had significantly lower body height, body length, hip width, and hucklebone width values compared to AG at 1.5 years old, and had significantly lower hip width, body length and hucklebone width compared to AG at 2 years old. At 2.5 years old, populations with genotype AA had significantly lower body length, hip width
\end{abstract}


and hucklebone width than AG individuals, with the exception of the Luxi breed, in which two genotypes were found. The Luxi and Ximentaer crossbreed had the lowest frequency of the G allele, while the highest $\mathrm{G}$ allele frequencies were found in the Luxi breed.

Key words: Cattle; SST gene; PCR-SSCP; Growth traits; SNPs

\section{INTRODUCTION}

The somatostatin (SST) is a cyclic tetradecapeptide, a member of the transforming growth factor (TGF- $\beta$ ) family, but not completely belonging to the current TGF- $\beta$ subfamily because of considerable differences, such as skeletal shape and morphogenetic protein and statin properties. SST is one of the most important genes in regulating animal growth and development, where it plays a negative role in animal growth regulation by inhibiting the release of growth hormone (GH), hindering the animal's growth. SST was originally isolated from the hypothalamus of sheep as a 14-amino acid peptide in 1973 by Brazeau. Its relative molecular mass is 1637 , including different forms of peptides, namely SST, SST14, SST28, and so on. SST is produced by neuroendocrine, inflammatory, and immune cells, in response to ions, growth factors, neuropeptides, and a series of cytokines. The peptide is released in large amounts from storage pools of secretory cells, or in some activated immune and inflammatory cells (Reichlin, 1983).

So far, six SST gene candidates were identified from the zebrafish genome database. Among them, SST1, SST2, SST3, and SST4 have been previously reported in vertebrates (Devos et al., 2002; Tostivint et al., 2008). Somatostatin 5 (SST5) and somatostatin 6 (SST6) are newly discovered (Liu et al., 2010). SST1 has been generally described in all vertebrates from agnathans to mammals (Andrews et al., 1988). All of these SSTs accomplish their diverse number of regulatory functions by interacting with high affinity somatostatin receptors (SSTR) in the plasma membrane (Bruno et al., 1992).

Along with the further study of the features of SST, a fairly large number of functions emerged. Due to its specialty of acting as an endogenous inhibitory regulator of the secretory and proliferative responses of target cells widely distributed in the brain and periphery and of hormone secretion in the pituitary gland, SST have an immeasurable effect on coordinating various aspects of growth, development and metabolism of animals through its inhibition of hormone secretions and cell proliferation and affecting nutrient absorption in the alimentary canal (Yamada et al., 1993; Kubota et al., 1994).

It is well known that growth in vertebrates is mainly controlled by GH (Planas et al., 2000; Butler and Le Roith, 2001). GH is produced and secreted in a manner reflective of the balance of stimulatory and inhibitory signals received by somatotrophs (Canosa et al., 2007). Evidence suggests that SST are the primary inhibitors of GH release (Very and Sheridan, 2002). Considering the vital function of GH in bovine growth and development and the inhibitory effect of SST on GH, as well as the rising living standard in our country, beef supply has become more and more insufficient and many weaknesses, such as slow growth, small body configuration and little amount of meat, exist in our cattle breeds, especially in the Qinchuan breed. The polymorphism of SST was detected and the correlation with growth traits was analyzed to provide preliminary scientific data for improving 
the establishment of meat production performance by a molecular screening system and the breeding of new beef cattle strains.

\section{MATERIAL AND METHODS}

\section{Sample collection data source}

Blood samples were collected from 694 unrelated Chinese cattle from Shaanxi, Henan and Shandong provinces in China belonging to the following six breeds: Qinchuan, QC (N = 389); Luxi, LX $(\mathrm{N}=64)$; Nanyang, $\mathrm{NY}(\mathrm{N}=48)$; Jiaxian, JX $(\mathrm{N}=73)$; Xianan, $\mathrm{XN}(\mathrm{N}=$ 67); Luxi and Ximentaer crossbreed, LXC $(\mathrm{N}=53)$. Many records of growth traits and body size including body length (BL), body height $(\mathrm{BH})$, waist height $(\mathrm{WH})$, rump length $(\mathrm{RL})$, hip width (HIP), chest depth (CD), chest circumference (CC), and hucklebone width (HW) of each individual from the different breeds mentioned above were collected for statistical analysis. Blood samples were taken back to the laboratory and stored at $-80^{\circ} \mathrm{C}$.

\section{DNA extraction}

Genomic DNA was isolated from blood samples following the traditional phenolchloroform extraction method and dissolved in sterile water at a concentration of $100 \mathrm{ng} / \mathrm{mL}$ and stored at $-20^{\circ} \mathrm{C}$, which was used for polymerase chain reaction-single-strand conformational polymorphism (PCR-SSCP) assays.

\section{Primer design and PCR amplification}

PCR primers (F 5'-GTTTGACCAACCGCACTC-3' and R 5'-AGTTAGGGGATTCG GGTG-3') were designed from the sequences reported (GenBank accession No. NC_007299) in order to amplify a 234-bp fragment of the single exon of SST gene spanning the G126A substitution. A $15-\mu \mathrm{L}$ reaction volume included $1 \mu \mathrm{L}(50 \mathrm{ng} / \mu \mathrm{L})$ template, $7.5 \mu \mathrm{L} 2 \mathrm{X}$ Taq PCR MasterMix, $5.9 \mu \mathrm{L} \mathrm{ddH}_{2} \mathrm{O}$, and $0.3 \mu \mathrm{L}$ of each primer $(10 \mu \mathrm{mol} / \mu \mathrm{L})$, performed in a Tpersonal thermocycler (Biometra) according to the following conditions: $95^{\circ} \mathrm{C}$ for $5 \mathrm{~min}$ (preliminary denaturation) followed by 31 cycles of $94^{\circ} \mathrm{C}$ for $30 \mathrm{~s}$ (denaturation), primer annealing at $57^{\circ} \mathrm{C}$ for $35 \mathrm{~s}$, and $72^{\circ} \mathrm{C}$ for $35 \mathrm{~s}$, and a final extension at $72^{\circ} \mathrm{C}$ for $10 \mathrm{~min}$. PCR products were then electrophoresed on $1.5 \%$ agarose gels using $1 \mathrm{X}$ TBE buffer ( $89 \mathrm{mM}$ Tris, $89 \mathrm{mM}$ boric acid, $2 \mathrm{mM} \mathrm{Na}_{2}$ EDTA), containing $200 \mathrm{ng} / \mathrm{mL}$ ethidium bromide to detect the product.

\section{SSCP and DNA sequencing}

To screen for polymorphism in the fragments analyzed, PCR amplicons were subjected to SSCP analysis. Four microliters of the PCR product was mixed with $9 \mu \mathrm{L}$ loading dye ( $98 \%$ formamide, $10 \mathrm{mM}$ EDTA, $0.025 \%$ bromophenol blue, and $0.025 \%$ xylene-cyanol) after denaturing at $98^{\circ} \mathrm{C}$ for $10 \mathrm{~min}$; the mixture was immediately chilled on ice for $10 \mathrm{~min}$. Afterward, the mixture was loaded on a 10\% acrylamide/bisacrylamide (29:1) gel and electrophoresed at $110 \mathrm{~V}$ for $14-20 \mathrm{~h}$ in $1 \mathrm{X}$ TBE buffer. Afterward, the polyacrylamide gel was 
silver stained with $0.1 \% \mathrm{AgNO}_{3}$ and revealed with $2 \% \mathrm{NaOH}$ (Lan et al., 2007). According to the PCR-SSCP band patterns that were visualized on the gels with the help of visual light, individual genotypes were defined ( $\mathrm{Qu}$ et al., 2005). Amplicons derived from the three allele standards were included on each gel for reference (Byun et al., 2008).

Representative PCR products corresponding to different mutation types that stand for homozygous individuals of different genotypes were chosen for DNA sequencing using primer 1 previously designed. Forward and reverse reactions were both performed to rule out false positives. With the DNAStar program, the sequencing results were blasted to specifically recognize the polymorphism type and location.

\section{Statistical analysis}

The genotypic and allelic frequencies in six cattle breeds were calculated by the $\chi^{2}$ test. Associations between genotypes of SNP1 (simple nucleotide polymorphism) of the SST gene and eight growth indices (BL, BH, WH, RL, HIP, CD, CC, and HW) and genetic effects were analyzed using the general linear model (GLM) procedure in Statistical Program for Social Sciences (SPSS), version 17.0, package, respectively. The following model were used:

$$
Y_{i j}=\mu+A_{i}+G_{j}+(A+G)_{i j}+E_{i j}
$$

where $Y_{i j}$ is the trait measured on cattle, $\mu$ is the population mean, $A_{i}$ is the fixed effect of age, $G_{j}$ is the fixed effect of genotype, $(A G)_{i j}$ is the interaction between the age and the genotype, and $E_{i j}$ is the random error. Significant differences between least-square means of different genotypes were determined using the Duncan multiple-range test, given that the trait was excluded from the model if its effect was not significant $(P>0.05)$. The values are reported as least square means and standard error of the means. P values of 0.05 were considered to be statistically significant (Lan et al., 2007).

\section{RESULTS}

\section{PCR-SSCP analysis}

The PCR-SSCP method was adopted for the identification of nucleotide sequence polymorphism of the bovine SST gene. The PCR products obtained at the most suitable temperature were detected, and the amplification result was satisfactory (Figure 1). The target fragment of the gene was amplified and denatured, and the polymorphism was found in the region of exon 1 (locus A) by polyacrylamide gel electrophoresis (Figure 2). In the region of exon 2, no polymorphisms were detected under all the possible electrophoretic conditions (Figure 3). By analyzing the PCR products of primer 1, three kinds of genotypes were detected in locus A by PCR-SSCP in the Luxi breed (Table 1). However, only two kinds of genotypes were found in the other five cattle breeds. This variant was confirmed by sequencing the PCR products from each genotype of chosen individual. The homozygote, consistent with the sequence of GenBank accession No. NC_007299, was named the AA genotype, another homozygote was named the GG genotype, and the heterozygote was named the AG genotype (Figure 4). 


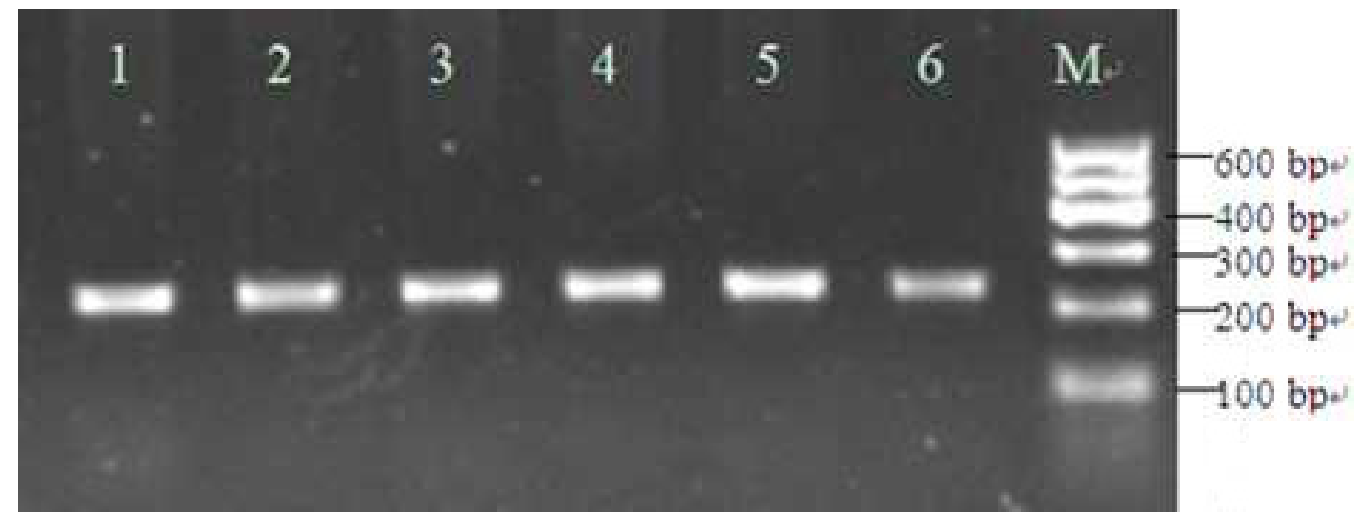

Figure 1. PCR amplification. Lanes 1- 6: PCR products; lane 7 = marker 1.

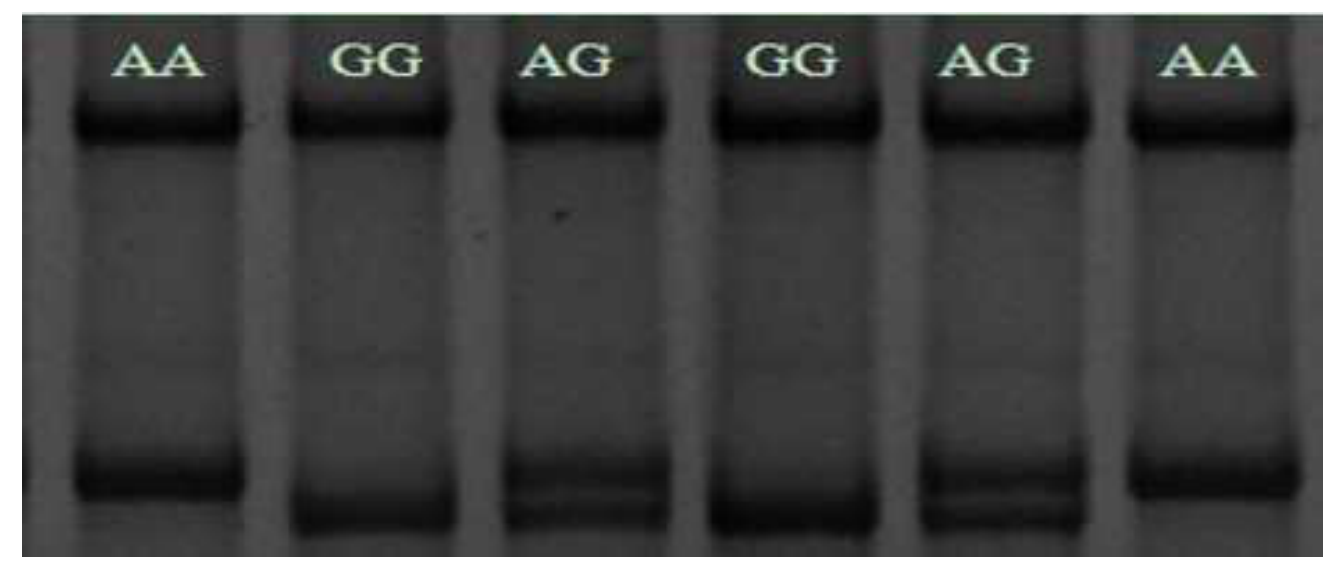

Figure 2. SST PCR-SSCP defined from genomic DNA amplifications on a silver-stained gel. The observed SSCP alleles are indicated at the bottom.

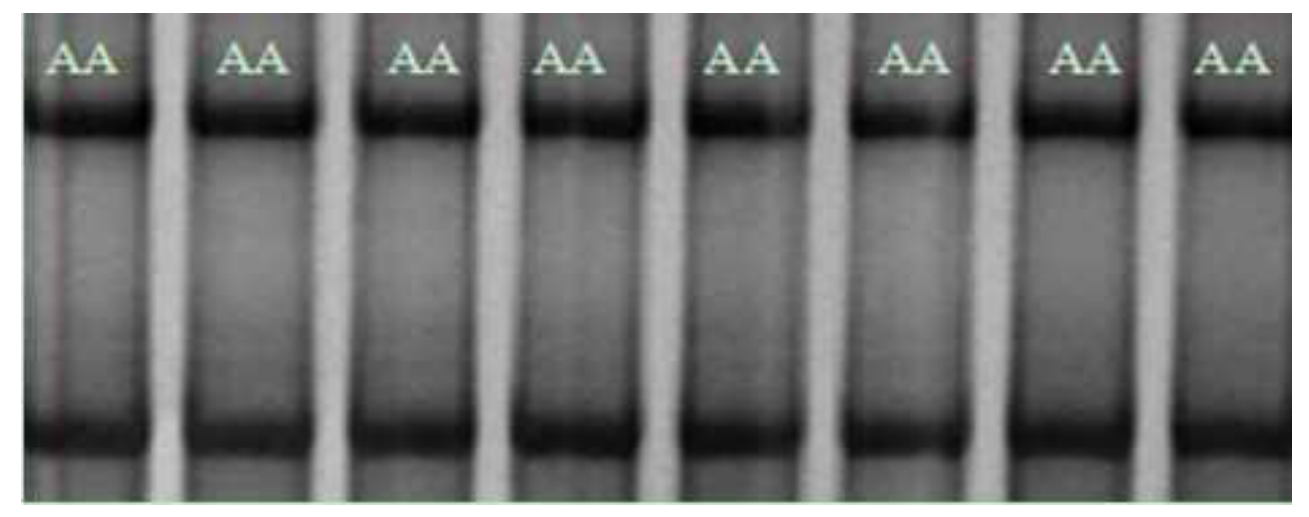

Figure 3. The PCR-SSCP of SST exon 2; no polymorphisms were detected. 


\begin{tabular}{|c|c|c|c|c|c|c|}
\hline \multirow[t]{2}{*}{ Breeds } & \multicolumn{3}{|c|}{ Observed genotypes } & \multirow[t]{2}{*}{ Total } & \multicolumn{2}{|c|}{ Haplotype frequencies } \\
\hline & $\mathrm{AA}$ & $\mathrm{AG}$ & GG & & A & G \\
\hline $\mathrm{QC}$ & 274 & 115 & 0 & 389 & 0.8522 & 0.1478 \\
\hline LX & 34 & 25 & 5 & 64 & 0.7266 & 0.2734 \\
\hline NY & 37 & 11 & 0 & 48 & 0.8854 & 0.1146 \\
\hline JX & 60 & 13 & 0 & 73 & 0.9110 & 0.0890 \\
\hline XN & 56 & 11 & 0 & 67 & 0.9179 & 0.0821 \\
\hline LXC & 47 & 6 & 0 & 53 & 0.9434 & 0.0566 \\
\hline
\end{tabular}
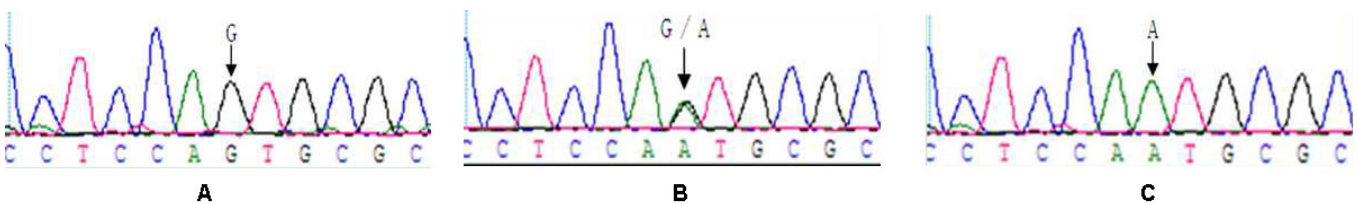

Figure 4. Sequences of three genotypes of SNP1 locus A (primer 1). A. Sequence of the AA genotype of SNP1 locus A (primer 1); B. Sequence of the AG genotype of SNP1 locus A (primer 1); C. Sequence of the GG genotype of SNP1 locus A (primer 1).

\section{Genotypic and allelic frequencies}

Each experimental individual was statistically analyzed with respect to the SST genotype. The frequency of genotype AG was low in the six breeds (QX, 0.2956; LX, 0.3906; NY, 0.2292; JX, 0.1781; XN, 0.1642; LXC, 0.1132), and genotype GG was only found in the Luxi breed. Accordingly, the frequency of allele $\mathrm{G}$ was very low in the six breeds (0.0566-0.2734) (Table 1).

The population genetic indices (gene homozygosity, gene heterozygosity (He), effective allele number (Ne), and polymorphism information content (PIC)) were calculated by the $\chi^{2}$ test (Table 2). The values of PIC and He of the Luxi breed in the loci were higher than that of other populations, which implied that the polymorphism and genetic variation of the Luxi breed were higher than that of other populations, showing higher polymorphism. Gene homozygosity varied from 0.6027 (LX) to 0.8932 (LXC), and Ne ranged from 1.1196 (LXC) to 1.6593 (LX). The maximum and minimum PIC values were 0.3184 (LX) and 0.1011 (LXC). This showed that it was relatively stable within the Chinese bovine SST gene in the populations analyzed except for the Luxi breed, indicating that more relevant study should be conducted on the Luxi breed.

\begin{tabular}{lcccc}
\multicolumn{5}{l}{ Table 2. Genetic diversity at SST gene exon 1 locus. } \\
\hline Breed & Homozygosity & Heterozygosity & Effective allele number & Polymorphic information content (PIC) \\
\hline QC & 0.7481 & 0.2519 & 1.3368 & 0.2202 \\
LX & 0.6027 & 0.3973 & 1.6593 & 0.3184 \\
NY & 0.7971 & 0.2029 & 1.2546 & 0.1823 \\
JX & 0.8378 & 0.1622 & 1.1936 & 0.1491 \\
XN & 0.8493 & 0.1507 & 1.1774 & 0.1393 \\
LXC & 0.8932 & 0.1068 & 1.1196 & 0.1011
\end{tabular}

PIC $>0.5$ means high diversity, $0.25<$ PIC $<0.5$ means moderate diversity, PIC $<0.25$ means low diversity. $\mathrm{QC}=$ Qinchuan cattle; $\mathrm{LX}=$ Luxi cattle; $\mathrm{NY}=$ Nanyang cattle; JX = Jiaxian cattle; XN = Xianan cattle; $\mathrm{LXC}=$ Luxi and Ximentaer crossbred cattle. 


\section{Correlation between SST gene polymorphisms and growth performance}

With the help of GLM estimation, the association analysis of the variant loci of SST gene of the Qinchuan breed and the growth indices was carried out (Table 3). Statistical differences were found in body length, body height, hip width, heart girth, and hucklebone width index of Qinchuan cattle at 1.5, 2, 2.5 years old. Multiple comparisons indicated that individuals with genotype AG had significantly higher values than those of individuals with genotype AA in body length, hip width, and hucklebone width at 1.5 and 2.5 years old $(\mathrm{P}<0.05)$. Individuals with genotype AG had significantly higher values than those of individuals with genotype AA in chest circumference at 2 years old, while for the body length and hucklebone width, the difference was very significant $(\mathrm{P}<0.01)$, which was the same as the body height index of 1.5 -year-old populations, respectively. No statistically significant differences were observed between the AG and AA genotypes in waist height, rump length and chest depth indices of Qinchuan cattle at various age stages.

\begin{tabular}{|c|c|c|c|c|}
\hline$\overline{\text { Age }}$ & Trait $(\mathrm{cm})$ & $\mathrm{AG}$ & AA & $P$ \\
\hline \multirow[t]{8}{*}{1.5 years old } & Body length & $128.50 \pm 4.198^{\mathrm{a}}$ & $117.15 \pm 2.852^{\mathrm{b}}$ & 0.039 \\
\hline & Body height & $118.00 \pm 1.970^{\mathrm{a}}$ & $108.85 \pm 1.338^{c}$ & 0.001 \\
\hline & Waist height & $122.33 \pm 5.285$ & $118.85 \pm 3.590$ & 0.592 \\
\hline & Rump length & $40.00 \pm 1.129$ & $39.00 \pm 0.767$ & 0.474 \\
\hline & Hip width & $39.00 \pm 1.450^{\mathrm{a}}$ & $35.23 \pm 0.985^{\mathrm{b}}$ & 0.046 \\
\hline & Chest depth & $63.17 \pm 2.003$ & $58.77 \pm 1.361$ & 0.087 \\
\hline & Chest circumference & $158.17 \pm 5.096$ & $147.00 \pm 3.462$ & 0.088 \\
\hline & Hucklebone width & $22.33 \pm 1.001^{\mathrm{a}}$ & $18.92 \pm 0.680^{\mathrm{b}}$ & 0.012 \\
\hline \multirow[t]{8}{*}{2 years old } & Body length & $134.63 \pm 2.472^{\mathrm{a}}$ & $123.25 \pm 2.331^{\mathrm{c}}$ & 0.002 \\
\hline & Body height & $120.13 \pm 1.656$ & $118.19 \pm 1.561$ & 0.402 \\
\hline & Waist height & $123.88 \pm 1.423$ & $123.75 \pm 1.342$ & 0.949 \\
\hline & Rump length & $43.66 \pm 1.113$ & $41.22 \pm 1.050$ & 0.121 \\
\hline & Hip width & $42.78 \pm 1.163^{\mathrm{a}}$ & $38.72 \pm 1.096^{\mathrm{b}}$ & 0.016 \\
\hline & Chest depth & $63.72 \pm 1.284$ & $63.89 \pm 1.210$ & 0.924 \\
\hline & Chest circumference & $169.59 \pm 3.198^{\mathrm{a}}$ & $157.61 \pm 3.016^{\mathrm{b}}$ & 0.01 \\
\hline & Hucklebone width & $26.41 \pm 1.057^{\mathrm{a}}$ & $21.61 \pm 0.996^{\mathrm{c}}$ & 0.002 \\
\hline \multirow{8}{*}{2.5 years old } & Body length & $133.57 \pm 2.856^{\mathrm{a}}$ & $125.80 \pm 1.951^{\mathrm{b}}$ & 0.036 \\
\hline & Body height & $119.43 \pm 2.188$ & $118.13 \pm 1.494$ & 0.630 \\
\hline & Waist height & $122.57 \pm 2.013$ & $123.53 \pm 1.375$ & 0.697 \\
\hline & Rump length & $43.93 \pm 1.277$ & $41.10 \pm 0.872$ & 0.082 \\
\hline & Hip width & $43.93 \pm 1.400^{\mathrm{a}}$ & $40.33 \pm 0.957^{b}$ & 0.047 \\
\hline & Chest depth & $65.64 \pm 1.544$ & $64.03 \pm 1.054$ & 0.399 \\
\hline & Chest circumference & $173.29 \pm 4.196$ & $163.00 \pm 2.867$ & 0.057 \\
\hline & Hucklebone width & $27.86 \pm 1.347^{\mathrm{a}}$ & $24.33 \pm 0.920^{\mathrm{b}}$ & 0.043 \\
\hline
\end{tabular}

${ }^{a, b}$ Different superscript letters in the same row indicate significant difference $(\mathrm{P}<0.05),{ }^{a, c}$ Different superscript letters in the same row indicate highly significant difference $(\mathrm{P}<0.01)$.

\section{DISCUSSION}

Up to now, there were very few reports about SST gene SNPs and their relationship with growth and development traits of animals, especially for cattle. Almost all research on SST focused on immune system, gain in weight and treatment for some neurologic and epidemical diseases (Patel, 1999; Kang et al., 2000). Our studies first examined SST as an candidate gene for bovine growth traits, using PCR-SSCP and DNA sequencing methods. One novel mutation, G126A, was found in exon 1, but no SNPs were found in exon 2. Some reports 
indicated that the SST gene was considerably conservative. This is a perfect confirmation. Through statistical analysis, the AA genotype showed a higher frequency than AG in six cattle breeds, while GG showed the lowest one. This result indicated that AA was the dominant genotype and A was the dominant allele. This discrepancy may be due to the species selection.

The relationship between SNPs in exon 1 and growth indices of the Qinchuan breed from 694 individuals was analyzed. The data in Table 3 showed that the AG genotype of G126A could increase body length, hip width and hucklebone width of cattle at different age stages. It is worth noting that these indices are potent indicators of cattle meat production. We can take some scientific measures to maintain the heterozygous gene (AG genotype) that can increase body length, hip width and hucklebone width, so as to promote the production of meat and solve a hot potato of low per capita consumption of meat production in China or even in the world.

Based on these results and from a functional point of view, the interesting allelic variant reported in the present study, which is identified in the exon region of the SNP G/A gene, may influence regulatory expression elements and could probably be used as markers for growth index in a cattle breeding program, and SST is likely a key gene that is a determinant in the improvement of growth in cattle breeds. Moreover, PIC was a perfect index for identifying the allele polymorphism, and it was also a reflection of the level of gene mutation. Our study showed that in the Luxi breed, PIC of locus A was 0.3184 , indicating a moderate level of polymorphism $(0.25<$ PIC $<0.5)$. Higher PIC demonstrates higher heterozygosis within an animal population, leading to more genetic alteration, which is beneficial for the genetic improvement of the correlated traits. Thus, it is possible that the Luxi breed may be a useful group, and it is worthy of further study.

Besides, because of the cost-efficient feature of PCR-SSCP for genotyping of the gene polymorphism at the population level and because it can provide an alternative to more sophisticated typing methods for small laboratories with limited resources, there is a growing interest in the detection and characterization of SNP markers for the purpose of paternity and identity confirmation (Heaton et al., 2002; Werner et al., 2004). The efficacy of polymorphisms depends on their information content. If the SST polymorphism is going to be tested in association studies in the population at large, it could be useful to include it in an SNP panel designed for the purposes mentioned above.

In conclusion, this study showed a new polymorphic locus (SNP1), which is meaningful for searching for more genetic markers. Through the correlation study on the polymorphism of SST and eight growth indices of Qinchuan cattle breed, the results indicated that this site was highly relevant to body length, hip width and hucklebone width features. Thus, adding cattle varieties, expanding samples and doing further correlation studies are still needed to accumulate quantitative molecular genetics data in studying the relationship between the SST gene and growth traits in cattle.

\section{ACKNOWLEDGMENTS}

Research supported by the China National 863 Program (\#2008AA1010 and \#2006AA10Z1A1), the National 11th Five-year Plan State Science and Technology Support Project (\#2006BAD01A103), GMO new varieties major project (\#2008ZX08007-002). Moreover, the bovine populations were supported by Qinchuan beef cattle breeding center of Shaanxi province, Nanyang, Jiaxian and Xianan cattle breeding center of Henan province, 
Luxi cattle breeding center of Shandong province, and Snow dragon beef cattle breeding center of Liaoning province (P.R. China).

\section{REFERENCES}

Andrews PC, Pollock HG, Elliott WM, Youson JH, et al. (1988). Isolation and characterization of a variant somatostatin-14 and two related somatostatins of 34 and 37 residues from lamprey (Petromyzon marinus). J. Biol. Chem. 263: 15809-15814.

Bruno JF, Xu Y, Song J and Berelowitz M (1992). Molecular cloning and functional expression of a brain-specific somatostatin receptor. Proc. Natl. Acad. Sci. U. S. A. 89: 11151-11155.

Butler AA and Le Roith D (2001). Control of growth by the somatropic axis: growth hormone and the insulin-like growth factors have related and independent roles. Annu. Rev. Physiol. 63: 141-164.

Byun SO, Fang Q, Zhou H and Hickford JG (2008). Rapid genotyping of the ovine ADRB3 gene by polymerase chain reaction-single-strand conformation polymorphism (PCR-SSCP). Mol. Cell Probes 22: 69-70.

Canosa LF, Chang JP and Peter RE (2007). Neuroendocrine control of growth hormone in fish. Gen. Comp. Endocrinol. 151: $1-26$

Devos N, Deflorian G, Biemar F, Bortolussi M, et al. (2002). Differential expression of two somatostatin genes during zebrafish embryonic development. Mech. Dev. 115: 133-137.

Heaton MP, Harhay GP, Bennett GL, Stone RT, et al. (2002). Selection and use of SNP markers for animal identification and paternity analysis in U.S. beef cattle. Mamm. Genome 13: 272-281.

Kang TC, Park SK, Do SG, Suh JG, et al. (2000). The over-expression of somatostatin in the gerbil entorhinal cortex induced by seizure. Brain Res. 882: 55-61.

Kubota A, Yamada Y, Kagimoto S, Shimatsu A, et al. (1994). Identification of somatostatin receptor subtypes and an implication for the efficacy of somatostatin analogue SMS 201-995 in treatment of human endocrine tumors. J. Clin. Invest. 93: 1321-1325.

Lan XY, Pan CY, Chen H, Zhang CL, et al. (2007). An AluI PCR-RFLP detecting a silent allele at the goat POU1F1 locus and its association with production traits. Small Ruminant Res. 73: 8-12.

Liu Y, Lu D, Zhang Y, Li S, et al. (2010). The evolution of somatostatin in vertebrates. Gene 463: 21-28.

Patel YC (1999). Somatostatin and its receptor family. Front. Neuroendocrinol. 20: 157-198.

Planas JV, Mendez E, Baños N, Capilla E, et al. (2000). Fish insulin, IGF-I and IGF-II receptors: a phylogenetic approach. Am. Zool. 40: 223-233.

Qu L, Li X, Wu G and Yang N (2005). Efficient and sensitive method of DNA silver staining in polyacrylamide gels. Electrophoresis 26: 99-101.

Reichlin S (1983). Somatostatin. N. Engl. J. Med. 309: 1495-1501, 1556-1563.

Tostivint H, Lihrmann I and Vaudry H (2008). New insight into the molecular evolution of the somatostatin family. Mol. Cell Endocrinol. 286: 5-17.

Very NM and Sheridan MA (2002). The role of somatostatins in the regulation of growth in fish. Fish Physiol. Biochem. 27: $217-226$.

Werner FA, Durstewitz G, Habermann FA, Thaller G, et al. (2004). Detection and characterization of SNPs useful for identity control and parentage testing in major European dairy breeds. Anim. Genet. 35: 44-49.

Yamada Y, Stoffel M, Espinosa R III, Xiang KS, et al. (1993). Human somatostatin receptor genes: localization to human chromosomes 14, 17, and 22 and identification of simple tandem repeat polymorphisms. Genomics 15: 449-452. 